Elsevier

PSP 00180

\title{
Event-related potentials in autistic and healthy children on an auditory choice reaction time task
}

\author{
R.D. Oades ${ }^{1}$, M.K. Walker ${ }^{2}$, L.B. Geffen ${ }^{1}$ and L.M. Stern ${ }^{3}$ \\ ${ }^{\prime}$ Department of Physiology, ' Department of Psychiatry, Flinders Medical Centre, Bedford Park, S.A. (Australia) \\ and ${ }^{3}$ Regency Park Centre for Young Disabled, Regency Park, S.A. (Australia)
}

(Accepted 11 September 1987)

Key words: Autism; Event-related potential; N1; P3; Lateralization; Attention

\begin{abstract}
Event-related potentials (ERPs) were recorded from midline $(\mathbf{F z}, \mathrm{Cz}, \mathrm{Pz})$ and lateral sites $\left(\mathbf{F}_{3}, \mathrm{~F}_{4}, \mathbf{P}_{3}, \mathbf{P}_{4}\right)$ in autistic children $(n=7)$ and age-matched controls $(n=9)$ on an auditory choice reaction time task. Subjects were asked to press a button to an infrequent target $(500 \mathrm{~Hz}, P=0.14)$ and to ignore higher pitched infrequent ( $2000 \mathrm{~Hz}, P=0.14)$ and frequent $(1000 \mathrm{~Hz})$ non-targets. Autistic subjects made twice as many errors of omission as controls and showed a higher criterion (beta) for targets. Maximum ERP peak amplitudes showed a more varied scalp distribution in the autistic group. N1 latencies were consistently shorter in the autistic group and in 3 subjects the target P3 latencies were markedly longer than for the controls. Compared to controls, the N1 amplitude of the autistic response was larger to the rare stimuli (particularly to non-targets). The amplitude of the P3 component was smaller in the autistic group (particularly to the target). The stimuli were also presented in a passive condition requiring no response. After subtraction of the waveform obtained in the passive condition from that obtained in the active condition or subtraction of the waveform elicited by the rare non-target from that elicited by the target, N1 target amplitude was larger in control than in autistic children. Autistic subjects showed more early negativity to the rare non-target at left frontal and a larger P3 to the target at right parietal sites. ERPs of autistic children are more responsive to stimulus features (e.g. high/rare non-target tone) and less responsive to their associations or meaningfulness (e.g. target P3). Attention-related ERPs of autistic children show signs of precocious (right dominance for P3) and delayed development (P3 not maximal at parietal sites).
\end{abstract}

\section{INTRODUCTION}

The syndrome of childhood autism, with a reported incidence of 5 in 10,000 (Ritvo and Freeman, 1978), can cover a wide range of disturbed abilities. These include sensory modulation and motility, comprehension and delivery of communication, relating to objects and to people (Kanner, 1943; Ornitz, 1985).

About $75 \%$ of autistic children may be mentally retarded (Rutter, 1983) Their cognitive problems range from amnesia, reminiscent of temporal lobe dysfunction (Boucher and Warrington, 1976;

Correspondence: R.D. Oades, Dalbergstr. 9, D-8755 Alzenau 3, F.R.G.
Boucher, 1981; Hetzler and Griffin, 1981) to difficulties with attention-demanding discriminations (Frankel et al., 1984; Miyashita, 1985; Damasio, 1984).

Investigations into the potential biological bases of dysfunction have not proved conclusive. A few cases of diffuse cerebral abnormalities have been found on autopsy (Williams et al., 1980; Bauman and Kemper, 1984) or with tomographic scans (Damasio et al., 1980; Campbell et al., 1982). Some evidence of partial cerebellar atrophy in non-retarded subjects has recently been found with the technique of nuclear magnetic imaging (Courchesne et al., 1987; personal communication June 1987). But it is not yet clear if these findings can be generalised.

Electrophysiological studies have produced 
contradictory results. But there is some evidence for 'hypervigilance' from the incidence of high frequency EEG (Hutt et al., 1965; Hermelin and O'Connor, 1970; Simeon and Itil, 1975) and a tendency for more abnormalities to appear in recordings from the left hemisphere (Tanguay, 1975; Dawson et al., 1982: Tsai and Stewart, 1982).

Perhaps the most productive line of investigation has been that into event-related potentials (ERPs). With adult subjects, the size of an early negative component (N1) has been related to stimulus deviance (Hink et al., 1978) or a mismatch with expectation (Näätänen et al., 1982), whereas that of a later positive component (P3) varies as a function of the probability of occurrence of a task-relevant event (Duncan-Johnson and Donchin, 1977). P3 latency increases with task difficulty (McCarthy and Donchin, 1976).

In normal children, ERP latencies are usually longer than in adults (Goodin et al., 1978; Halliday et al., 1984). Shorter latencies than normal have been reported for auditory and visual P1, N1, P2 and P3 components in autistic children (Small, 1971; Saletu et al., 1975; Martineau et al., 1984a; Courchesne et al., 1984, 1985). In a variety of situations $\mathrm{N} 1$ and P3 amplitudes are often smaller than in healthy control children (Small et al., 1969; Small, 1971; Ornitz et al., 1972; Lelord et al., 1973; Novick et al., 1980; Niwa et al., 1983; Martineau et al., 1984b; Courchesne et al., 1984; 1985). Although reduced $P 3$ amplitudes have been recorded for autistic children in no-task situations whether the stimuli were novel (Courchesne et al., 1984) or not (Niwa et al., 1983), increased P3 amplitudes are reported after non-target stimuli in an auditory two-tone discrimination (August et al., 1984).

We proposed to extend previous work by comparing features of a number of ERPs in an attention-demanding 3-tone auditory choice reaction time task (ACRT: Pfefferbaum et al., 1984). In particular we were interested to see if autistic subjects showed differential ERP responses to rare stimuli (target and non-target). Further, in the absence of reports of ERPs from lateral recording sites, we studied the distribution of changes over lateral frontal and parietal sites. We hoped this would throw light on the development of regional function, where the autistic nervous system is said to show impaired development (Ornitz, 1985). We compared a group of healthy children matched for age and sex with a small group of autistic children (on placebo) studied in a clinical trial of fenfluramine (Stern et al., submitted).

\section{METHODS}

\section{Subjects}

Seven autistic children diagnosed by a psychiatrist, paediatrician and psychologist according to DSM III criteria of the American Psychiatric Association and 9 normal healthy control subjects were matched for chronological age. Four other autistic children were tested from a pool of 21, but they did not produce enough data for analysis. Of 13 healthy children examined, 7 were selected whose age came within 7 months of an autistic subject and the mean for the group did not exceed that for the autistic group. Two further subjects were included whose ages partially offset the divergent verbal and non-verbal mental ages of two autistic subjects (see Table I). There was one female in each group. Attempts to match for mental age proved impracticable. All preferred to use their right hand.

Reports from parents, children and clinicians indicated that hearing was normal in all subjects. This was confirmed in some by pure tone audiometry. Others were non-compliant and hearing was estimated to be normal after iripedance audiometry and vocabulary tests.

\section{Psychometric assessment}

The Leiter and British Ability Scale (BAS) tests of intelligence were administered to both groups. The Leiter scale allowed autistic subjects a better chance of comprehension as the tests were presented non-verbally. Thus autistic performance could be fairly compared with controls on the Leiter scale up to about age 15 years and was used to calculate I.Q. (Table I). The BAS is a general test of intelligence presented verbally and was used to calculate mental age. But it can be subdivided into verbal and non-verbal (visual) components. As an estimate of I.Q. in subjects of 15 
years or more, the non-verbal component was used. As Wechsler scales are commonly used in the South Australian public education system, it was decided not to administer these tests in order to avoid a confounding learning effect. In contrast, the BAS has rarely and the Leiter scale has never been used here before.

\section{General procedure}

The laboratory was visited by children with their parents or guardians and all tests were conducted in the morning according to a protocol approved by the Flinders Medical Centre Clinical Investigations Ethics Committee. A familiarization visit was followed by another on which ERP recordings were made. During task presentation subjects sat in a sound-attenuated room under subdued lighting and were asked to look at a point in front of them during the $\triangle C R T$ task.

\section{$A C R T$}

The auditory paradigm is adapted from Pfefferbaum et al. (1984). Computer-generated pseudorandom sequences of 3 pure tones with different frequencies and probabilities of occurrence $(500$ $\mathrm{Hz}, P$ 0.14; $1000 \mathrm{~Hz}, P$ 0.72; $2000 \mathrm{~Hz}, P$ 0.14) were played through Telephonic earphones (TDH$49 \mathrm{P}$ ) at $50 \mathrm{dBSL}$ (SL default value $20 \mathrm{~dB}$ ) against a background of white noise at $20 \mathrm{~dB}$ above threshold (intertrial interval min. $500 \mathrm{~ms}$; max. $1300 \mathrm{~ms}$ ). The two rare tones could not occur in succession. The tones lasted $100 \mathrm{~ms}(10 \mathrm{~ms}$ rise $/ 10$ ms fall).

Tones were presented in 140-trial blocks lasting about $4 \mathrm{~min}$ in passive and active conditions. In the passive condition, subjects were asked to listen to the tones and keep still. In the active condition subjects were asked to press a button with the right hand to each low tone $(n=20)$. The button (a microswitch) was located on a response panel and required a pressure of $100 \mathrm{~g}$ for operation. In addition to the ERP, the reaction time, errors of omission and commission ( $\mathrm{d}^{\prime}$ and beta), the number of trials accepted and those rejected through artifact, slow or fast responses were recorded (Fig. 1).

A passive session was presented before and after the active sessions to control for (1) stimulus features of the ERP to the target tone, (2) lasting effects of learning acquired during the active session. As the latter were not apparent they will not be discussed further. Three active trial blocks were presented with short rest pauses between. Training and practice was required between the first passive block and the active blocks. The instructions emphasised, in order of importance, keeping still, accuracy and speed.

\section{Data acquisition and recording procedures}

Electroencephalographic activity was recorded from tin electrodes located in midline frontal $(\mathrm{Fz})$, central $(\mathrm{Cz})$ and parietal $(\mathrm{Pz})$ and from lateral sites $\left(F_{3}, F_{4}, P_{3}, P_{4}\right)$. A vertical electro-oculogram was recorded from an electrode close to the supraorbital ridge of the right eye. An electrode cap (ACI, Electrocap International) was used. Subjects were grounded with an electrode on the forehead and all activity referenced to linked earlobes. Electrode impedances ranged from less than 3 to a maximum of $6 \mathrm{kohm}$.

Grass P511 K amplifiers with an upper and lower half-amplitude cut-off of 30 and $0.01 \mathrm{~Hz}$, respectively, and a $50-\mathrm{Hz}$ notch filter were used at an EEG amplification of $5 \times 10^{4}$ (EOG, $5 \times 10^{3}$ ). Data, managed on-line by an LSI $11 / 73 \mathrm{com}$ puter, were digitized at a sample rate of $1 \mathrm{~ms}$ for 1 $\mathrm{s}$ beginning $100 \mathrm{~ms}$ before stimulus onset. Trials on which the EEG was contaminated by movement artifact were eliminated if one in ten samples exceeded threshold $( \pm 90 \mu \mathrm{V})$.

\section{Data analysis}

All peak measures (latency, amplitude and area) were computed from voltages averaged with respect to the $100 \mathrm{~ms}$ prestimulus epoch for each tone-stimulus condition separately. EEG waveforms were digitally filtered $(-3 \mathrm{~dB}$ at $15 \mathrm{~Hz}$, half amplitude $21 \mathrm{~Hz}$ ). Peak negativity was sought in the following windows (ms, post-stimulus): N1, 120-240; N2, 240-400; P1, 50-150; P2, 150-300; P3, 300-600; P4, 600-900; SW, 650-900 ms. (P3 waves were taken as the more positive wave in the P3 or P4 window.) Early averaged negativity was also sought $(0-400 \mathrm{~ms})$.

Individual subjects were averaged and grand 
mean data were analysed. Firstly the distribution of N1, P2 and P3 peak maxima between the three midline recording sites was investigated (Table II). Subsequent analysis for these waves was carried out at frontal, central and parietal sites, respectively. In addition to baseline measures, two subtraction procedures were performed. In the first the waveform elicited by the rare non-target was subtracted from that elicited by the target in the active condition: in the second the waveform elicited by the low ('target') stimulus in the passive condition, where no response was required, was subtracted from that elicited by the target in the active condition. The early negativity arising from similar procedures has been termed mismatch and processing negativity, respectively (Näätänen and Michie, 1979; Näätänen et al., 1982).

Unless otherwise stated, analysis of ERP components was performed using a multivariate, repeated measures analysis of variance with and without covariates for chronological age and I.Q. followed by post-hoc Tukey tests (two-tailed). Behavioural and derived measures were analysed by paired $t$-tests for related samples. Pearson correlation coefficients for I.Q. were also calculated.

\section{RESULTS}

\section{Subjects}

Chronological age, mental age and I.Q. values are shown for individual subjects in Table I. Whilst the matching for chronological age between groups was confirmed, the I.Q. of the autistic subjects was lower than that for the controls $(t=-2.45$, $P<0.04)$.

\section{Task performance}

Control reaction times were slightly longer than in the autistic group (592 (S.E.M. 20) vs 557 (S.E.M. 33) $\mathrm{ms} ; \quad P<0.05$ ). I.Q. correlated more with the reaction times of autistic $(0.94 ; P<0.005)$ than that of control children (0.6; $P<0.09)$.

Errors of omission were twice as numerous in

TABLE I

Individual subject data

\begin{tabular}{|c|c|c|c|c|c|}
\hline & & $\begin{array}{l}\text { Chrono- } \\
\text { logical/age } \\
\text { (months) }\end{array}$ & $\begin{array}{l}I . Q . \\
\text { Leiter } \\
\text { scale }\end{array}$ & $\begin{array}{l}\text { Mental } \\
\text { age (months) } \\
\text { (Leiter) }\end{array}$ & $\begin{array}{l}\text { Mental age } \\
\text { (months) } \\
(B A S)\end{array}$ \\
\hline \multirow[t]{7}{*}{ Autistic subjects } & 1 & 212 & $(98)^{*}$ & - & 191 \\
\hline & 2 & 69 & 69 & 69 & 54 \\
\hline & 3 & 96 & 136 & 90 & 112 \\
\hline & 4 & 141 & 87 & 123 & 97 \\
\hline & 5 & 116 & 139 & 94 & 115 \\
\hline & 8 & 177 & 98 & 156 & 157 \\
\hline & 9 & 139 & 46 & 65 & 61 \\
\hline Mean/median & & $136 / 139$ & $90 / 94$ & $112 / 115$ & $115 / 107$ \\
\hline \multirow[t]{9}{*}{ Control subjects } & 15 & 135 & 121 & 163 & 151 \\
\hline & 16 & 148 & 104 & 154 & 166 \\
\hline & 17 & 182 & $(121)^{*}$ & - & 235 \\
\hline & 18 & 95 & 141 & 133 & 115 \\
\hline & 19 & 83 & 135 & 112 & 98 \\
\hline & 21 & 68 & 137 & 93 & 94 \\
\hline & 22 & 107 & 142 & 151 & 136 \\
\hline & 23 & 176 & 123 & 212 & 208 \\
\hline & 24 & 205 & $(87)^{*}$ & - & 175 \\
\hline Mean/median & & $113 / 135$ & $123 / 123 * *$ & $141 / 151$ & $153 / 151$ \\
\hline
\end{tabular}

* Based on British Ability Scale non-verbal rating: ** $P<0.05$. 
TABLE II

Scalp distribution for maximum ERP peaks amplitudes: number of autistic (A) and control (C) subjects with maxima at recording sites $F z$, $\mathrm{Cz}$ and $\mathrm{Pz}$

\begin{tabular}{|c|c|c|c|c|c|c|c|c|c|c|}
\hline \multirow{2}{*}{$\begin{array}{l}\text { Stimulus: } \\
\text { Site: }\end{array}$} & & \multicolumn{3}{|c|}{ Target } & \multicolumn{3}{|c|}{ Rare non-target } & \multicolumn{3}{|c|}{ Common non-target } \\
\hline & & $\mathrm{Fz}_{\mathrm{z}}$ & $\mathrm{Cz}$ & $\mathrm{Pz}$ & $\overline{\mathrm{Fz}}$ & $\mathrm{Cz}$ & $\overrightarrow{\mathrm{Pz}}$ & $\overline{\mathrm{Fz}}$ & $\mathrm{Cz}$ & $\overline{\mathrm{Pz}}$ \\
\hline \multirow[t]{2}{*}{ N1 } & A & 4 & 3 & 0 & 4 & 0 & 3 & 3 & 2 & 2 \\
\hline & $\mathrm{C}$ & 9 & 0 & 0 & 2 & 0 & 7 & 5 & 1 & 3 \\
\hline \multirow[t]{2}{*}{ P2 } & A & 2 & 3 & 2 & 1 & 5 & 1 & 1 & 5 & 1 \\
\hline & $\mathrm{C}$ & 0 & 6 & 3 & 0 & 5 & 4 & 0 & 7 & 2 \\
\hline \multirow[t]{2}{*}{ P3 } & A & 3 & 2 & 2 & 0 & 2 & 5 & 2 & 2 & 3 \\
\hline & $\mathrm{C}$ & 0 & 2 & $7^{*}$ & 0 & 4 & 5 & 0 & 3 & 6 \\
\hline
\end{tabular}

* P3 maximum at $\mathrm{Pz}$ in $\mathrm{Cs}$ rather than more rostrally in As, $P<0.05$ (Fisher test).

the autistic group (36.2 (S.E.M. 11.8) vs 10.7 (S.E.M. 2.0) $t=2.13 ; P<0.037$ ). There were too few errors of commission to justify separate analysis, (five autistic subjects scored $<1.5 \%$ ). Signal detection measures showed that the major difference in task performance between groups was represented by a higher criterion (beta) rather than a change of sensitivity (autistic, 11.9 vs con- trol, $6.7 ; t=2.3 ; P<0.03$ ). For controls I.Q. correlated with omission errors and beta (both 0.8 ; $P<0.01$ ). This was not so for the autistic group $(r=-0.6 ; P<0.2$ and $r=-0.5, P<0.3$ respectively).

\section{Distribution of ERP maxima}

For the control group, P3 maxima to all three
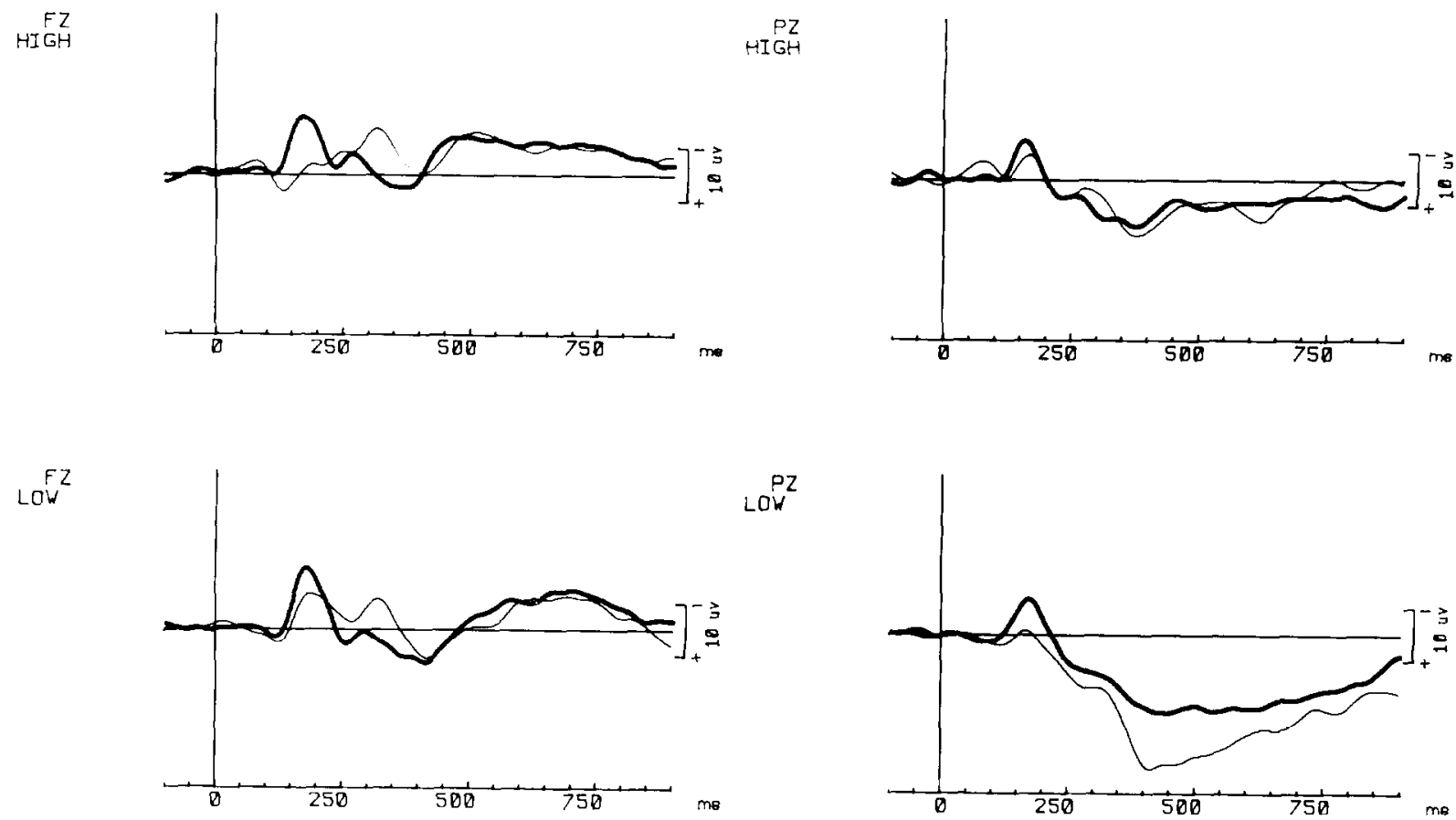

Fig. 1. Grand mean wave forms elicited by the low (target stimulus) and high (rare non-target stimulus) recorded at Fz (two left-hand diagrams) and $\mathrm{Pz}$ (two right-hand diagrams) for autistic (thick trace) and control children (thin trace). 


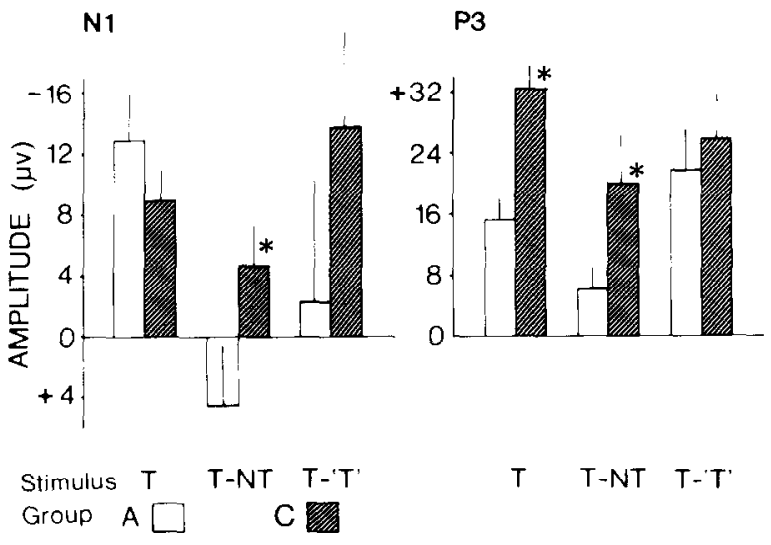

Fig. 2. The diagram shows $\mathrm{N} 1$ and $\mathrm{P} 3$ amplitudes $(\mu \mathrm{V})$ elicited by target stimuli ( $T$ ) on the left of each figure for autistic (A) and control (C) subjects. From these values, the amplitude elicited by the rare non-target (NT) has been subtracted (centre of each figure). Component amplitudes resulting from presentation of the 'target' stimulus in the passive condition (where no button push was required) were subtracted from those elicited in the active condition on the right of the diagram $\left(\mathrm{T}-{ }^{\top} \mathrm{T}\right) .\left({ }^{*} P<0.05\right)$.

tones usually occurred at $\mathrm{Pz}$, whereas $\mathrm{P} 2$ maxima usually occurred at the vertex. N1 components were clearly maximal frontally, except to the rare non-target tone where more subjects showed a $\mathrm{Pz}$ maximum (Table II).

Autistic subjects showed a more varied distribution of amplitude maxima for all ERP components elicited by each tone. The distribution was most similar for autistic and control subjects for ERPs elicited by the frequent non-target. The distribution of $\mathrm{N} 1$ and $\mathrm{P} 2$ maxima elicited by the target was similar but slightly more diffuse. To the target, autistic subjects showed a tendency for the $\mathrm{P} 3$ component not to peak at $\mathrm{Pz}$ as in the control group $(P<0.05$, Fisher test $)$.

\section{Midline ERPS}

The acceptance rate for ERP data elicited by the target tones was not significantly different between the control $(50 \%)$ and the autistic group (30\%) $(t=1.4 ; \quad P<0.2)$. The rate of rejection through movement artifact was similar for both groups $(36-40 \%)$. There were no significant differences on measures of the N60, P2 and P2-N2 components.

NI component. N1 latencies to all three stimuli were longer for controls (Table III). After covarying for age or I.Q., there was a significant main effect of condition ( $\mathrm{df}=1.11, F=4.6, P<0.05$ ). Post-hoc tests of the nominal data were not significant, but ranking the data showed a longer latency to frequent non-targets $(U=7 ; P<0.05$. 2-tail).

N1 amplitudes were larger in the autistic group after all stimuli, but this was particularly marked for rare non-targets and if the baseline to peak measure was replaced by the $\mathrm{P} 1-\mathrm{N} 1$ measure. Irrespective of covariate, there was a condition by measure interaction $(\mathrm{df}=2.26, F=4.2, P<0.03$; Fig. 1). Post-hoc analysis showed a significantly

TABLE III

Latency and amplitude of $N I(F z)$ and $P 3(P z)$ recorded after low (target), high and common (non-target) tone stimuli in autistic and control groups

\begin{tabular}{|c|c|c|c|c|c|c|c|c|c|c|c|c|}
\hline \multirow{4}{*}{$\begin{array}{l}\text { ERP: } \\
\text { Tone: }\end{array}$} & \multicolumn{12}{|c|}{ Measure } \\
\hline & \multicolumn{6}{|c|}{ Latency (ms) } & \multicolumn{6}{|c|}{ Amplitude (we) } \\
\hline & \multicolumn{3}{|l|}{ NI } & \multicolumn{3}{|l|}{$P 3$} & \multicolumn{3}{|l|}{$N 1$} & \multicolumn{3}{|l|}{$P 3$} \\
\hline & Low & High & Common & Low & High & Common & Low & High & Common & Low & $H i g h$ & Common \\
\hline \multicolumn{13}{|l|}{$\overline{\text { Grotp }}$} \\
\hline $\begin{array}{l}\text { Autistic } \\
\text { (S.E.M.) }\end{array}$ & $\begin{array}{l}179 \\
(6.7)\end{array}$ & $\begin{array}{l}167 \\
(9.5)\end{array}$ & $\begin{array}{l}167 \\
(3.4)\end{array}$ & $\begin{array}{l}471 \\
(28.6)\end{array}$ & $\begin{array}{l}430 \\
(26.4)\end{array}$ & $\begin{array}{l}464 \\
(49.9)\end{array}$ & $\begin{array}{l}-13.0 \\
(3.1)\end{array}$ & $\begin{array}{l}-17.6 \\
(5.0)\end{array}$ & $\begin{array}{l}-10.0 \\
(2.5)\end{array}$ & $\begin{array}{l}15.6 \\
(2.5)\end{array}$ & $\begin{array}{l}9.5 \\
(2.5)\end{array}$ & $\begin{array}{l}5.4 \\
(1.2)\end{array}$ \\
\hline $\begin{array}{l}\text { Control } \\
\text { (S.E.M.) }\end{array}$ & $\begin{array}{l}190 \\
(7.3)\end{array}$ & $\begin{array}{l}184 \\
(8.7)\end{array}$ & $\begin{array}{l}178+ \\
(11.4)\end{array}$ & $\begin{array}{l}459 \\
(19.8)\end{array}$ & $\begin{array}{l}411 \\
(21.3)\end{array}$ & $\begin{array}{l}410 \\
(26.5)\end{array}$ & $\begin{array}{l}-9.0 \\
(2.0)\end{array}$ & $\begin{array}{l}-4.3^{*} \\
(3.6)\end{array}$ & $\begin{array}{l}-5.1 \\
(2.4)\end{array}$ & $\begin{array}{l}33.6 * \\
(3.6)\end{array}$ & $\begin{array}{l}11.8 \\
(4.2)\end{array}$ & $\begin{array}{l}6.0 \\
(2.3)\end{array}$ \\
\hline
\end{tabular}

+ See text, ${ }^{*} P<0.05$. 
larger N1 in the autistic group was elicited by the rare non-target (no covariate) and by the target after covarying for age $(P<0.05)$. For control subjects alone the target $\mathrm{N} 1$ amplitude correlated positively with I.Q. $(0.85 ; P<0.004)$.

As the autistic response to non-targets was unusually large, we hypothesized that the larger target $\mathrm{N} 1$ amplitude might be attributable to features other than its being the target (e.g. rarity). Therefore we subtracted firstly the amplitude difference between the two rare stimuli (T - NT) and secondly we substracted the amplitude difference elicited by the target in the active and the same tone in the passive conditions $T-$ ' $T$ '). Disap- pearance of the $\mathrm{N} 1$ after subtraction procedures would be consistent with our hypothesis. Residual target N1 amplitudes might reflect attention-related processes or task difficulty. With the former procedure (T - NT), the N1 amplitude of control subjects was halved, but the larger negativity in the autistic group was removed altogether (Fig. 2: $t=1.91, P<0.04)$. There was a negative correlation with I.Q. for the autistic subjects $(-0.9$; $P<0.01)$. In the latter case $\left(T-{ }^{\prime} \mathrm{T}\right)$, negativity in the control group was enhanced with respect to the reduced N1 amplitude shown by autistic subjects. But the result was not statistically significant (Fig. $2: t=1.1 ; P<0.14$ ). This may be attributa-
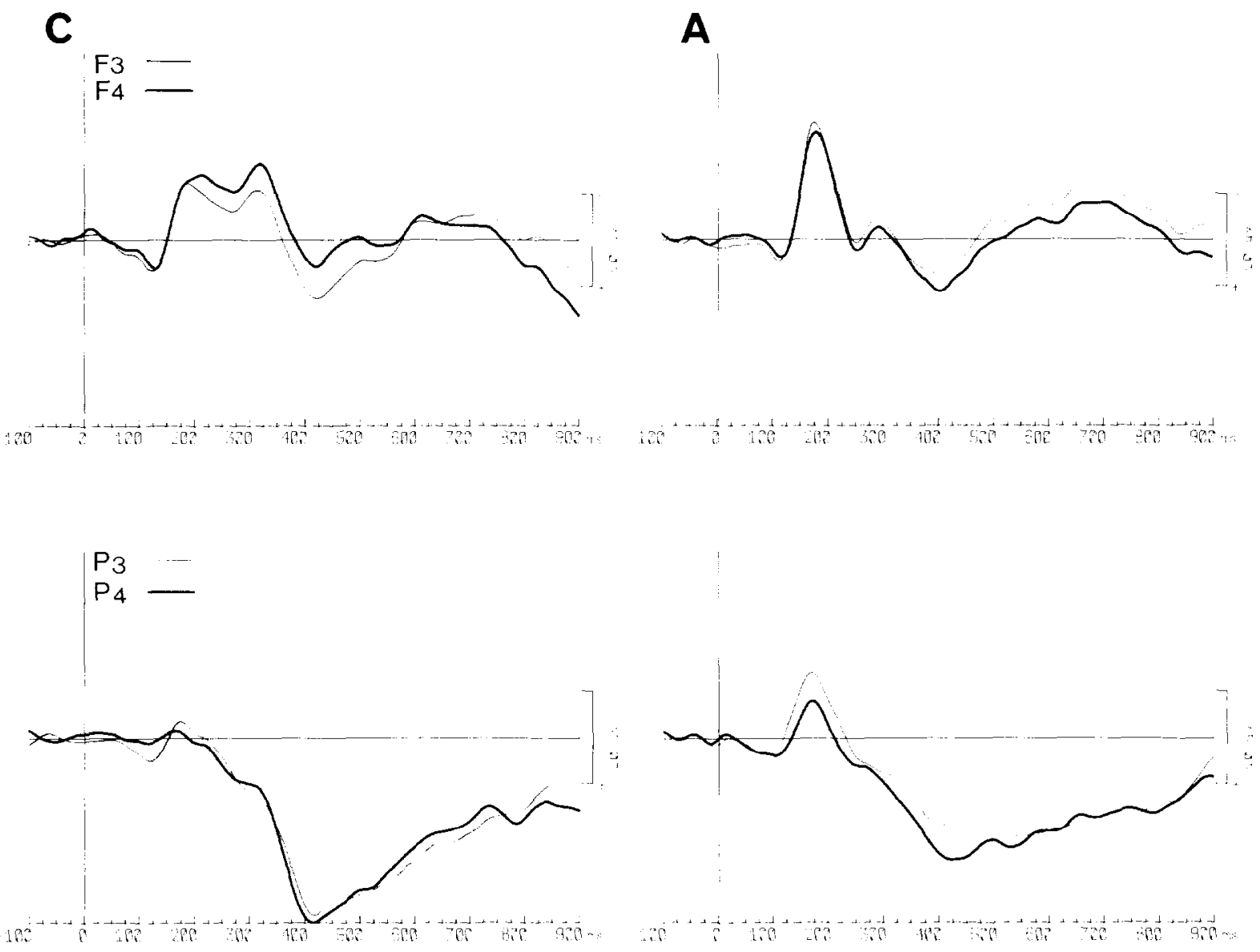

Fig. 3. Grand mean waveforms elicited by the target stimulus recorded at lateral frontal $\left(F_{3}\right)$ and parietal sites $\left(P_{3}\right)$ and right frontal $\left(\mathrm{F}_{4}\right)$ and parietal sites $\left(\mathrm{P}_{4}\right)$ in autistic (two left-hand diagrams) and control children (two right-hand diagrams). 
ble to the large standard error of the data.

P3 component. There were no significant differences of P3 latency between autistic and control groups (Table 2). But three autistic subjects did show markedly longer latencies $(500-600 \mathrm{~ms})$.

Analysis of P3 amplitudes showed a marked condition by measure interaction $(\mathrm{df}=2.28, F=$ 4.5, $P<0.02)$ irrespective of covariate. This was due to the target P3 amplitude of control subjects being more than twice that of the autistic group $(P<0.05$, Table II, Fig. 1). This difference remained after subtraction of the components elicited by the two rare stimuli (Fig. $2: t=-2.1$, $P<0.03$ ), but disappeared when the components elicited by the 'target' in the passive condition were subtracted from those elicited in the active condition (Fig. 2: $t=-0.54, P<0.6$ ). There were no correlations of any P3 measure with I.Q.

Slow wave ( $S W$ ) components. After all stimuli, there were no significant differences of early average negativity (SW1, $0-400 \mathrm{~ms}, \mathrm{Fz}$ ) or late average positivity ( $S W 2,650-900 \mathrm{~ms}, \mathrm{Pz}$ ), with or without subtraction procedures between autistic and control subjects.

\section{Lateral ERPs}

After target and non-target stimuli, N1 latency was longer in the right hemisphere $\left(F_{4}\right)$ but the amplitude was larger over the left hemisphere $\left(F_{3}\right)$ in both subject groups (Table IV). However, after the rare non-target, early negativity (SW 1; 0-400 ms) was larger in the left hemisphere for autistic and in the right hemisphere for control children.
On analysis of variance this proved not significant $(\mathrm{df}=3.36, F=1.4, P<0.25)$. We recently observed a significant change to similar values of SW1 as shown by the controls, in autistic children after treatment with fenfluramine. With this determining our null hypothesis, the current results reach 1-tail significance $(t=-2.0 ; P<0.04)$.

Data for the P3 component were more variable, particularly in the autistic group. In contrast to $N 1$, the target P3 latency was longer in the left hemisphere $\left(P_{3}\right)$ in controls. Whereas controls showed little lateralization for P3 amplitude, for autistic subjects the amplitude was larger after the target in the right hemisphere $\left(\mathrm{P}_{4}\right)$ (Fig. 3; Table 4). An analysis of variance did not prove significant, but, as above, paralleling the effects of fenfluramine treatment in autism, P3 amplitude after the target was larger over the autistic right hemisphere $(t=+1.7, \quad P<0.05 \quad 1$-tail $)$. To a lesser extent this was reflected in late positivity (SW2; 650-900 ms; Table IV).

\section{DISCUSSION}

Autistic children, who were mildly retarded with respect to healthy control subjects, were overselective in the performance of the ACRT. They showed increased omission errors and decreased reaction times. Whilst N1 latencies were shorter than in controls, P3 latencies were variable and often longer. Large $\mathrm{N} 1$ amplitudes were largely attributable to increased responsiveness of autistic sub-

TABLE IV

Records from lateral frontal $(F)$ and lateral parietal $(P)$ sites of latenct and amplitude of earty negatire (NI and SWI) and late positive ERPS (P3 and SW2) elicited by target (T) and non-target (NT) tones (S.E.M.)

Positive values represent longer latency or larger amplitude over right hemisphere. negative values represent larger values over left hemisphere.

\begin{tabular}{|c|c|c|c|c|c|c|c|c|}
\hline \multirow[t]{2}{*}{ Subjects } & \multicolumn{2}{|l|}{$N I(F)$} & \multicolumn{2}{|l|}{$S W 1(F)$} & \multicolumn{2}{|l|}{$P 3(P)$} & \multicolumn{2}{|l|}{$S W 2(P)$} \\
\hline & $T$ & $N T$ & $\bar{T}$ & $N T$ & $\bar{T}$ & $\overline{N T}$ & $\bar{T}$ & $\bar{N} T$ \\
\hline Autistic latency & $+3.3(1.7)$ & $+4.6(5.3)$ & & & $+1.6(6.9)$ & $-19.9(33.1)$ & & \\
\hline Control latency & $+3.0(3.1)$ & $+3.0(5.3)$ & & & $-4.9(3.1)$ & $-8.7(13.3)$ & & \\
\hline Autistic amplitude & $-1.6(3.4)$ & $-1.2(1.0$ & $+1.5(4.1)$ & $-3.9(2.6) *$ & $+5.3(2.8) *$ & $-1.1 \quad(2.3)$ & $+3.1(2.5)$ & $+1.5(2.2)$ \\
\hline Control amplitude & $-1.7(1.1)$ & $-2.1(1.6)$ & $+2.0(3.6)$ & $+2.2(1.7)$ & $+0.1(1.6)$ & $+0.7(1.8)$ & $-0.9(2.0)$ & $+2.3(1.6)$ \\
\hline
\end{tabular}

$* P<0.05$. 
jects to rare stimuli. Target-elicited P3 amplitudes in the autistic group were smaller. ERP maxima showed a more variable distribution in the autistic group. There was a tendency for autistic subjects to show more left frontal early negativity after non-targets and more right parietal late positivity after target stimuli.

Task performance. Could the poorer performance of the autistic group on the ACRT be attributed to their being more impulsive? The slightly shorter reaction times shown by the autistic group might indicate that they were more impulsive. In adult populations, increased reaction time has often been associated with improved task performance. Indeed I.Q. correlated with reaction time in our study. However, in the near absence of errors of commission on the ACRT, the implication of greater impulsivity seems unlikely to be an important factor. In this respect, the autistic group differs from children with attention deficit disorder (Oades, 1987) who usually show low beta values and an improved performance is associated with increased beta.

In controls, the rigidity of criterion (beta) was $55 \%$ that of the autistic group. This implies that the autistic group was impaired in selectively attending to targets and recognizing them as meaningful stimuli. With increased rigidity of criterion, they appear to be overselective. Overselectivity has been previously recognised as a problem in autistic children (Hermelin and $\mathrm{O}^{\prime}$ Connor, 1970; Rutter, 1983; Miyashita, 1985). Emphasis should not be placed on signal detection measures based on highly discriminable tones. But, despite the frequency difference between stimuli, several potential subjects were unable to perform the discrimination. The number of omission errors shown by controls was $30 \%$ of that shown by the autistic group. Although this is consistent with an interpretation in terms of overselectivity, it is difficult to rule out impaired concentration and vigilance in autistic children.

The amount of movement artifact in the ERP recordings could be taken as an indirect index of motor activity (e.g. fidgetiness). It is of interest that the two groups of children showed the same degree of activity on this measure. Although motility can be a factor in autism (see Introduction), it does not seem important in the relatively high functioning group studied here. Those with lower I.Q. are likely to show more motor disturbance (Stern et al., submitted).

ERP topography. Clearly, there are differences in the distribution of ERP maxima over the scalp between the groups that probably reflect diffuse changes in the sites of generators for some but not all of the ERP components. The tendency for the P3 component of autistic subjects not to be maximal at $\mathrm{Pz}$ could be taken as an indicator of impaired development (cf. Ornitz, 1985). But this should not be overemphasized as the control group did not show the same degree of lateralisation as autistic subjects of the parietal site (see below). Rather, the reverse argument, derived from reports of a 'hypermature' EEG in autistic subjects (Stevens and Milstein, 1970), may have relevance. Supporting this line of reasoning, we note that autistic subjects showed clearer frontal maxima for early negative components than the controls. The clearer frontal N1 and lateralised responses at parietal sites might reflect greater synchrony of neural activity within these two areas. Indeed a greater inter-regional synchrony has been resported for learning disabled children from records of evoked potentials from 10 sites in three sensory modalities (Sutton et al., 1986).

Midline ERPs. In autistic children, N1 latencies were usually shorter and P3 latencies longer to all stimuli. In some individuals the changes were marked.

Two related questions should be asked about the early negative component. Is it an $\mathrm{N} 1$ wave and to what extent do endogenous (attention-related) and exogenous (stimulus-related) features contribute to it? This component showed a late onset in both subject groups and for autistic subjects it was larger than usual (references in introduction). The latency is comparable to the $\mathrm{N} 2 \mathrm{~b} /$ mismatch negativity (e.g. Sams et al., 1986), which is said to reflect orientation to a stimulus deviating from the standard. However, its main contribution is to the second negative component of the ERP which in our subjects is probably seen at a latency of $300 \mathrm{~ms}$. (As some subjects did not show a recognisable second negative component after standard stimuli, we could not perform a 
meaningful analysis of ' $N 2 b$ ' after a subtraction procedure.) Thus we do not rule out a contribution from the construct underlying the $\mathrm{N} 2 \mathrm{~b}$, but the component is not the major one we describe as N1 (latency ca. $170 \mathrm{~ms}$ ).

With regard to latency, we also note that $\mathrm{Nc}$, which may be the first ERP to appear in development, has an appropriate onset latency (up to 250 $\mathrm{ms}$ ). It may provide a contribution to our recorded N1 amplitude, but it usually lasts longer and may have a greater influence on the wave forms we recorded after $450 \mathrm{~ms}$ (Courchesne et al., 1981). This difference may be a result of the different tasks used. Nc is said to represent the focussing of attention on recent information analogous to Näätänen's (1982) frontal component of the processing negativity seen in adults (Courchesne et al., 1986). This supports our own interpretation of the residual negativity after subtracting waveforms (see below). Indeed, the topographic distribution of the negativity remaining after subtraction shows reduced potentials anteriorly in autistic subjects, but a similar magnitude to the controls posteriorly (unpublished data). This leads to the second question of exogenous versus endogenous influences on the ' $\mathrm{N} 1$ '.

Increased stimulus salience could have been an exogenous factor influencing the N1 of autistic children. We cannot entirely exclude this from our hearing controls. However our ' $\mathrm{N} 1$ ' amplitude differences were not significant for standard stimuli or those passively presented. For autistic subjects, ' $N 1$ ' amplitudes were larger to both rare stimuli, whereas for controls there was no amplitude difference to the rare or common nontarget stimuli (cf. Table III). Rarity, however, may not be the critical feature for autistic children. The discrimination of tones separated by an octave can be more difficult than for tones with a smaller or larger separation (Born, personal communication). It might be that by asking a learning-disabled group of children to discriminate rare tones an octave apart, the task was made too difficult. Future studies should pay attention to this question. Nonetheless, from this study it is suggested that autistic subjects are sensitive to exogenous stimulus features.

ERPs were recorded in conditions requiring a response to the low tone (active) and one requiring no response (passive). Subtraction of the ERPs elicited in the passive from those in the active presentation should show that proportion of the ERP relating to the significance of the target, separate from other features such as frequency, but, in contrast to the procedure of subtracting rare-non-target from target ERPs, controlling for pitch. Both subtraction procedures ( $T$ - ' $T$ '; $T$ NT) produced similar results for ' $\mathrm{N} 1$ '. The result is reminiscent of the difference negativity $(\mathrm{Nd})$ described by Hansen and Hillyard (1980). (But note that these authors did not vary frequency of stimulus presentation or interstimulus interval.) $\mathrm{Nd}$ has a later onset and lasts longer than N1. Our variation of this measure contributed to the $\mathrm{N} 1$ component of healthy but not autistic children (Fig. 2). We conclude that, in contrast to exogenous factors, the small endogenous component of the ' $N 1$ ' is much reduced in the autistic group.

In the baseline-active condition, $\mathrm{N} 1$ amplitudes were larger to both rare stimuli, but particularly to the rare non-target. P3 amplitudes were smaller after target stimuli. As the N1 changes were correlated with I.Q., but the P3 changes were not, we would predict that the former might be related to learning disability in general and the latter to the problems of autistic children in particular.

This underreaction of autistic subjects to meaningful stimuli is confirmed by the smaller baseline P3 and the small amount of positivity remaining after subtraction of the ERP elicited by the rare non-target. This characteristic can also be seen after subtraction of 'target'-ERPs, in the passive from the active condition (Fig. 2). But little or no meaning can be attached to the absolute P3 values in this situation as individual latencies varied $200-300 \mathrm{~ms}$. Inspection of Fig. 3 illustrates the point. It could be argued that the functional cerebral activity represented by the 'P3' component in the autistic group lies at one of several points after about $425 \mathrm{~ms}$. Speculatively the extensive distribution of low levels of positivity, both in time after a stimulus (Fig. 3) as well as between one target and two non-larget stimuli (Fig. 1, Table IV), could reflect a lack of control in the allocation of capacity for late information processing. 
Although other studies have used different recording and stimulus presentation procedures, their results support our basic finding that nontarget auditory stimuli elicit larger P3 components in autistic than in normal children (Novick et al., 1980; Niwa et al., 1983; August et al., 1984).

Lateralised ERPs: Autistic subjects showed similar weak lateralization tendencies to the control group with regard to early negative components, except that rare non-targets elicited left not right hemisphere activation as in controls. However, whereas controls showed little lateralization for later positive components, the autistic group showed a right hemisphere activation.

An increased early negative SW after the rare non-target could imply increased arousal or activation of the left hemisphere (Born et al., 1986). That is to say the 'mismatch' of the rare non-target with expectation elicited more of a (negative-going) response (cf. Näätänen and Michie, 1979). As this was only in response to the non-target, this could mean that autistic children expended more effort to attend to and inhibit response to an irrelevant but salient stimulus (cf. Duncan-Johnson and Donchin, 1977). This effect might be exaggerated if autistic subjects were peculiarly sensitive to high tones. We are not aware of evidence to support this suggestion. The possibility could be addressed by counterbalancing the tone-frequency of rare targets and nontargets. This was not included in the present protocol as it was considered that consistency was preferable in such a small subject group.

The target stimulus elicited a little more late positivity in the right hemisphere $\left(\mathrm{P}_{4}\right)$ of autistic than control children. Even in the resting condition, the EEG amplitude has recently been reported to be larger over right posterior sites in autistic children than in controls matched for chronological and mental age (Cantor et al., 1986). It is interesting that in a study of children at risk for schizophrenia, Friedman et al. (1986) found more late negativity in the high risk group, but in a range of subjects showing attentional deviation, they reported a large positive slow wave. Thus, although both the paradigm (continuous performance test) and the subjects were quite different, there may nonetheless be features, such as the nature of attentional dysfunction, that the groups have in common.

Thus, we find some evidence for unusual activation in left and right hemispheres of autistic children. This result diverges from studies of very young autistic children with whom, paradoxically, an absence of the normal development of EEG lateralization in task performance (Dawson et al., 1982, 1983), sleep (Ogawa et al., 1982) and an absence of normal lateralised ERP differences (Tanguay, 1975) have been reported. Our results indicate that there may be differences in both hemispheres. This argues against a specific lateralised deficit. Rather, there appears to be dysjunctive coordination of cerebral activity between the two hemispheres with respect to earlier and later stages of information processing. A disturbance in the connections between brain regions has been postulated to underly the problems of learningdisabled children (Geschwind, 1965; Sevush and Heilman, 1984). Indeed less interhemipheric EEG coherence has been reported for such groups of children (Sklar et al., 1973; Montagu, 1975). It would probably be worthwhile recording such slow wave changes in future studies involving larger numbers of subjects than were available to us.

Conclusions. We confirm that autistic children are unusually overselective. Their performance on the ACRT showed increased omission errors and a shorter reaction time. These seem to be related to factors measured by I.Q. Shorter N1 latencies may be related to shorter reaction times in autistic children. But with several autistic children showing abnormally long P3 latencies there must be some decoupling in the cerebral processes indexed by these or intervening components. We attribute the larger N1 amplitude of autistic children to their responsiveness to features of rarity rather than salience or pitch. The small P3 component suggests that the autistic children have difficulty in attaching significance to the target stimuli. We postulate from the variability in the distribution of ERP maxima and the more negative left frontal and more positive right parietal potentials, that autistic children may have difficulty in coordinating neural activity between distant sites both in the rostrocaudal and lateral dimensions.

Our deductions are based on a very small sam- 
ple of relatively high functioning autistic children. We included no learning -disabled control group. For these reasons it would be premature to generalise from our results. Nonetheless, despite the possibility that our autistic data, taken during the placebo-phase of a clinical trial, may show a 'placebo effect', major differences in comparison with a control group were found. By recording early and later ERP components from a number of sites in an attention-demanding paradigm, we believe we have been able to describe the nature of the attention-related problems of our subjects more closely than has previously been attempted. It would be interesting to study the conflict autistic children have in resolving stimulus rarity from meaningfulness in more than one task, with larger numbers of subjects and with a learning control group.

\section{ACKNOWLEDGEMENTS}

This research was performed with financial assistance from the Channel 10 children's fund of South Australia, Apex and the Flinders University research budget. We are grateful for research assistance from Mrs. J. Gotch, for statistical assistance from Mr. N. Bluhm and table preparation by Ms. J. Dodwell. We thank Drs. M. Wright, C.R. Clark and Mr. J. Altree-Williams for helpful advice and discussion.

\section{REFERENCES}

August, G.J., Raz, N., Papanicolaou, A.C., Baird, T.D., Hirsh, S.L. and Hsu, L.L. (1984) Fenfluramine treatment in infantile autism: neurochemical, electrophysiological and behavioral effects. J. Nerv. Ment Dis., 172: 604-612.

Bauman, M.L. and Kemper, T.L. (1984) The brain in infantile autism. A histoanatomic case report. Neurology, 34: (suppl. 1) 275 .

Born, J., Fehm-Wolfsdorf, G., Lutzenberger, W., Voigt, K.H. and Fehm, H. (1986) Vasopressin and electrophysiological signs of attention in man. Peptides, 7: 189-193.

Boucher, J. (1981) Memory for recent events in autistic children. J. Aut. Dev. Disord., 11: 293-303.

Boucher, J. and Warrington, E.K. (1976) Memory deficits in early infantile autism: some similarities to the amnesic syndrome. Br. J. Psychol., 67: 73-87.
Campbell, M., Rosenbloom, S., Perry, R., George, A.E. Kricheff, I.I., Anderson, L., Small A.M. and Jennings, S.J. (1982) Computerized axial tomography in young autistic children. Am. J. Psychiatry, 139: 510-512.

Cantor, D.S.. Thatcher, R.W., Hrybyk, M. and Kaye, H. (1986) Computerized EEG analyses of autistic children. I. Aur. Dev. Disord., 16: 169-187.

Courchesne, E., Elmasian, R. and Yeung-Courchesne, R. (1986) Electrophysiological correlates of cognitive processing: P3b and Nc basic, clinical and developmental research. In A.M. Halliday, S.R. Butler and R. Paul (Eds.), A. textbook of Clinical Neurophysiologr, Wiley, London, pp. 645-676.

Courchesne, E., Ganz, L. and Norcia, A. (1981) Event-related potentials to human faces in infants. Child Dev. 52: $804-811$.

Courchesne, E.. Kilman, B., Galambos, R. and Lincoln, A.J. (1984) Autism: processing of novel auditory information assessed by event-related potentials. EEG Clin. Neurophysiol., 59: 238-248.

Courchesne, E., Hesselink, J.R., Jernigan, T.L. and YeungCourchesne, R. (1987). Abnormal neuroanatomy in a nonretarded person with autism. Unusual findings with magnetic resonance imaging. Arch. Neurol., 44: 335-341.

Courchesne, E., Lincoln, A.J., Kilman, B.A. and Galambos, R. (1985) Event-related potential correlates of the processing of novel visual and auditory information in autism. $J$. Aut. Dev. Disord., 15: 55-76.

Damasio, A.R. (1984) Autism. Arch. Neurol., 41: 481.

Damasio, II., Maurer, R.G., Damasio, A.R. and Chui, H.C. (1980) Computerized tomographic scan findings in patients with autistic behavior. Arch. Neurol, 37: 504-510.

Dawson, G., Warrenberg, S. and Fuller, P. (1982) Cerebral lateralization in individuals diagnosed as autistic in early childhood. Brain Lang., 15: 353-368.

Dawson, G., Warrenburg, S. and Fuller, P. (1983) Hemisphere functioning and motor imitation in autistic persons. Brain Cogn., 2: 346-354.

Duncan-Johnson, C.C. and Donchin, E. (1977) On quantifying surprise: the variation in event-related potentials with subjective probability. Psychophysiology, 14: 456-467.

Frankel, F., Simmons, J., Fichter, M. and Freeman, B. (1984) Stimulus overselectivity in autistic and mentally retarded children - a research note. J. Child Psychol. Psychiatry, 25: 147-155.

Friedman, D., Cornblatt, B., Vaughan, H. and ErlenmeyerKimling, L. (1986) Event-related potentials in children at risk for schizophrenia during two versions of the continuous performance test. Psychiatr. Res, 18: 161-177.

Geschwind, N. (1965) Disconnexion syndromes in animals and man. Brain, 88:237-294.

Goodin, D., Squires, K., Henderson, B. and Starr, A. (1978) Age-related variations in evoked potentials to auditory stimulation in normal subjects. EEG Clin. Neurophysiol, 44: $447-458$.

Halliday, R., Callaway, E. and Lynch, M. (1984) Age, stimulant drug and practice effects on P3 latency and concurrent reaction time. Ann. N.Y. Acad. Sci., 425: 357-361. 
Hansen, J.C. and Hillyard, S.A. (1980) Endogenous brain potentials associated with selective auditory attention. $E E G$ clin, Neurophysiol., 49: 277.290.

Hermelin, B. and O'Connor, N. (1970) Psychological Experiments with Autistic Children, Pergamon, Oxford.

Hetzler, B.E. and Griffin, J.L. (1981) Infantile autism and the temporal lobe of the brain. J. Aut. Dev. Disord., 11: $317-330$

Hink, R.F., Fenton, W.H., Pfefferbaum, A., Tinklenberg, J.R. and Kopell, B.S. (1978) The distribution of attention across auditory input channels: an assessment using the human auditory potential. Psychophysiology, 15: 466-473.

Hutt, S.J., Hutt, C., Lee, D. and Ounsted, C.A. (1965) behavioural and electroencephalographic study of autistic children. J. Psychiatr. Res., 3: 181-198.

Kanner, L. (1943) Autistic disturbances of affective contact. Nervous Child., 2: 217-250.

Lelord, G., Laffont, F., Jusseaume, P. and Stephant, J.L. (1973) Comparative study of conditioning of averaged evoked reponses by coupling sound and light in normal and autistic children. Psychophysiology 13: 81-85.

Martineau, J., Garreau, B. Barthelemy C. and Lelord, G. (1984a) Evoked potentials and P300 during sensory conditioning in autistic children. Ann. N.Y. Acad. Sci, 425: $362-369$.

Martineau, J., Barthelemy, C., Garreau, B., Tanguay, P., Bruneau, N. and Lelord, G. (1984b) Relations entre les potentiels evoques auditifs (presence, amplitude) an cours du conditionnement son-lumiere et les taux de derives de la dopamine dans l'autisme de l'enfant. Rev. EEG Neurophysiol. 14: 139-148.

McCarthy, G. and Donchin, E. (1976) The effects of temporal and event uncertainty in determining the waveforms of the auditory event-related potential. Psychophysiology, 13: $581-590$.

Miyashita, T. (1985) Visual discrimination learning with variable irrelevant cues in autistic children. J. Aut. Dev. Disord., 15: $399-408$.

Montague, J.D. (1975) The hyperkinetic child: a behavioral, electrodermal and EEG investigation. Dev. Med. Child Neurol., 17: 299-305.

Näätänen, R. and Michie, P.T. (1979) Early selective attention effects on the evoked potential: a critical review and reinterpretation. Biol. Psychol. 8: 81-136.

Näätänen, R., Simpson, M. and Loveless, N.E. (1982) Stimulus deviance and evoked potentials. Biol. Psychol., 14: 53-98.

Niwa, S., Ohta, M. and Yamazaki, K. (1983) P300 and stimulus evaluation process in autistic subjects. J. Aut. Dev. Disord., 13: 33-42.

Novick, B., Vaughan, H.G., Kurtzberg, D. and Simson, R. (1980) An electrophysiologic indication of auditory processing defects in autism. Psychiatr. Res., 3: 107-114.

Oades, R.D. (1987) Attention deficit disorder with hyperactivity $(\mathrm{ADDH})$ : the contribution of catecholaminergic activity. Prog. Neurobiol., 29: 365-391.

Ogawa. T.. Sugiyama. A., Ishiwa, S., Suzuki, M., Ishihara. T. and Sato, K. (1982) Ontogenic development of EEG asymmetry in early infantile autism. Brain Dev., 4: 439-449.

Ornitz, E.M. (1985) Neurophysiology of infantile autism. $J$. Am. Acad. Child Psychiatry, 24: 251-262.

Ornitz, E.M., Tanguay, P.E., Lee, J.C.M., Ritvo, E.R. Sivertsen, B. and Wilson, C. (1972) The effects of stimulus interval on the auditory evoked response during sleep in autistic children. J. Aut. Child. Schizophr., 2: 140-150.

Pfefferbaum, A., Ford, J.M., Wenegrat, B.G., Roth, W.T. and Kopell, B.S. (1984) Clinical application of the P3 component of event-related potentials. EEG Clin. Neurophysiol., 59: $85-103$

Ritvo, E.R. and Freeman, B.J. (1978) National society for autistic children: definition of the syndrome of autism. $J$. Am. Acad. Child Psychiatry, 17: 565-576.

Rutter, M. (1983) Cognitive deficits in the pathogenesis of autism. J. Child Psychol. Psychiatry, 24: 513-531.

Saletu, B., Saletu, M., Itil, T.M. and Simeon, J. (1975) Brain function analysis in childhood psychosis: evoked responses. Clin Electroencephalogr., 6: 44-53.

Sams, M., Paavilainen, P., Alho, K. and Näätänen, R. (1986) Auditory frequency discrimination and event-related potentials. EEG Clin Neurophysiol., 62: 437-448.

Sevush, S. and Heilman, K.M. (1984) A case of literal alexia: evidence for a disconnexion syndrome. Brain Lang., 22: 92-108.

Simeon, J. and Itil, T.M. (1975) The computerised electroencephalogram. A model of understanding the brain function in childhood psychosis and its treatment. J. Aut. Child. Schizophr., 5: 247-265.

Sklar, B., Hanley, J. and Simmons, W.A. (1973) A computer analysis of EEG; spectral signatures for normal and dyslexic children. IEEE Trans. Biomed. Eng., 20: 21-26.

Small, J.G. (1971) Sensory evoked responses of autistic children. In D.W. Churchill, G.D. Alpern and M.K. DeMyer (Eds.), Infantile Autism, C.C. Thomas, Springfield, pp. 224-242.

Small, J.G., DeMeyer, M.K. and Kendall, J.K. (1969) Experience with response averaging in autistic children. $E E G$ Clin. Neurophysiol., 26: 112-113.

Stevens, J.R. and Milstein, V. (1970) Severe psychiatric disorders of childhood: electroencephalogram and clinical correlates. Am. I. Disabl. Child, 120: 182-192.

Sutton, J.P., Whitton, J.L., Topa, M. and Moldofsky, H. (1986) Evoked potential gaps in learning disabled children. EEG Clin. Neurophysiol., 65: 399-404.

Tanguay, P.E. (1975) Clinical and electrophysiological research. In E. Ritvo (Ed.), Autism: Diagnosis, Research, Management, Spectrum, New York, pp. 75-84.

Tsai, L.Y. and Stewart, M.A. (1982) Handedness and EEG correlation in autistic children. Biol. Psychiatry, 17: 595-597.

Williams, R.S., Hauser, S.L., Purpura, D.P., Delong, G.R. and Swisher, C.N. (1980) Autism and mental retardation: neuropathologic studies performed in four retarded persons with autistic behavior. Arch. Neurol., 37: 749-753. 